\title{
Mechanical properties of polypropylene composites reinforced with alkaline treated pineapple leaf fibre from Josapine cultivar
}

\author{
A.N. Kasim ${ }^{1 *}$, M.Z. Selamat ${ }^{1}$,M.A.M. Daud ${ }^{1}$, M.Y. Yaakob ${ }^{1}$, A. Putra ${ }^{1}$ \\ and D. Sivakumar ${ }^{1}$ \\ ${ }^{1}$ Centre of Advanced Research on Energy (CARe), \\ Faculty of Mechanical Engineering, \\ UniversitiTeknikal Malaysia Melaka,Hang Tuah Jaya, \\ 76100 Durian Tunggal, Melaka, Malaysia. \\ *Email: ayunatasyakasim@yahoo.com \\ Phone: 019-5703102
}

\begin{abstract}
This study investigates the mechanical properties of high impact polypropylene composite reinforced with pineapple leaf fibre from the Josapine cultivar as a function of fibre loading. PLF was extracted by using a pineapple leaf fibre machine and then an alkaline treatment was conducted to enhance the properties. Samples of the composite were fabricated with $100 \mathrm{~mm}$ fibre length with five different fibre loadings of PLF (30, 40, 50, 60 and $70 \mathrm{wt} \%$ ). The fabrication was made by a compression moulding technique with unidirectional fibre orientation. Related tests such as tensile, hardness and density tests were conducted to determine the effect of fibre loading. The experimental data showed that the composite with the $60 \mathrm{wt} \%$ fibre loading offered the highest value of tensile strength, which was about 309\%, and the Young's modulus was about 540\% compared to $0 \mathrm{wt} \%$ of PLF loading. Meanwhile, the hardness and density of the PLF/PP composites showed very similar values, with small increments from $30 \mathrm{wt} \%$ up to $70 \mathrm{wt} \%$ PLF loading compared to $0 \mathrm{wt} \%$ of PLF loading. The highest values are 65.38 Shore-D and $1.002 \mathrm{~g} / \mathrm{cm}^{3}$ respectively. The results also revealed that PLF from the Josapine cultivar with alkaline treatment greatly influences the mechanical properties of PLF/PP composite.
\end{abstract}

Keywords: Pineapple leaf fibre; polypropylene; fibre reinforced polymer.

\section{INTRODUCTION}

Recently, researchers have shown an increased interest in the development of biodegradable fibre reinforced polymer (BFRP) composite as a replacement for conventional materials, especially in the automotive, marine, packaging, furniture and building construction industries [1-4]. The production of green material natural fibre composites is becoming very attractive and is widely practised, due to the problems of global warming and oil depletion [5]. Prasad and Rao [6] stated that natural fibre plays an important role in developing biodegradable composites to resolve the current ecological and environmental problems [7,8]. Additionally, the use of natural fibre composites offers a combination of excellent mechanical properties, dielectric properties, and environmental advantages such as low density, low cost, reasonable specific strength, high toughness, being recyclable, biodegradable, renewable and carbon dioxide $\left(\mathrm{CO}^{2}\right)$ neutral [4]. Many types of natural fibres are being used nowadays. Some of the fibres that 
have been investigated by researchers for use in the natural composite industry include: rice husk [1, 5, 9-11], pineapple leaf [10, 12-22] bamboo [22-25], coir [25], jute, sisal, kapok [26], coconut [27] and oil palm [28]. In this study pineapple leaf fibre from a Malaysian cultivar (Josapine) was used as a reinforcing material and the matrix used is polypropylene.

Pineapple leaf fibre (PLF) from Malaysian cultivars has huge potential to be used as a reinforcing material in natural composite products or textile materials [29]. This is because Malaysia is one of the world's major producers of pineapple, but only the fruit is used while the leaf, whose main content is fibre, is burnt or thrown away, thus causing pollution and wasting the best potential sources of natural fibre $[13,14]$. Hence, the use of PLF in the natural composite materials industry can reduce environmental pollution, waste disposal problems and ecological concerns, especially in Malaysia. Mohamed et al. [13] studied the characterization of PLF from selected Malaysian cultivars. They found that Josapine cultivar has the best properties in terms of the quantity of fibre, fineness of fibres, thermal stability, tensile strength and modulus compared with the Sarawak and Moris cultivars, as shown in Table 1 [13]. However, the utilization of natural fibre has a significant drawback, which is its high moisture adsorption and poor wettability with some polymer matrix [30]. This problem can be overcome by treating these natural fibres with a suitable treatment such as alkaline treatment or heat treatment with the aim of modifying the surface of the natural fibres and improving the adhesion between the hydrophilic natural fibre and hydrophobic polymer matrix [3, 18, 31]. Siregar et al. [32] reported on the effects of alkaline treatments on the tensile properties of PLF reinforced high impact polystyrene composites. Their results revealed that the use of PLF with alkaline treatment improved the tensile strength and tensile modulus of the composites. The objective of the present work is to study the use of PLF from the Josapine cultivar with alkaline treatment as reinforcement to improve the mechanical properties of polypropylene composite. This research focused on the fibre extraction process and surface modification of PLF with alkaline treatment. The mechanical properties of PLF/PP composite such as tensile stress, hardness and bulk density are observed.

Table 1. Properties of different types of cultivars of PLF [14].

\begin{tabular}{lccc}
\hline \multirow{2}{*}{ Property } & \multicolumn{3}{c}{ Cultivar } \\
\cline { 2 - 4 } & Moris Gajah & Josapine & Sarawak \\
\hline Average no. of leaves & 50 & $65-70$ & $65-70$ \\
Length of leaves $(\mathrm{mm})$ & 63 & 61 & 70 \\
Width of leaves $(\mathrm{mm})$ & 61 & 46 & 65 \\
No. of fibre bundles per leaf & 90 & 80 & $>100$ \\
Diameter $(\mu \mathrm{m})$ & $120-440$ & $105-300$ & $170-340$ \\
Tensile strength $(\mathrm{MPa})$ & 174.89 & 293.08 & 148.44 \\
Young's modulus $(\mathrm{GPa})$ & 7.45 & 18.94 & 10.46 \\
Elongation at break $(\%)$ & 0.52 & 1.41 & 1.05 \\
\hline
\end{tabular}

\section{MATERIALS AND METHODS}

\section{Materials}

Polypropylene in powder form $(250 \mu \mathrm{m})$ with the types of impact polypropylene from Lotte Chemical Titan was used as the polymer matrix, as shown in Figure 1(a). Pineapple leaves from Josapine cultivars were collected from cultivation areas in Pontian, Johor 
Malaysia. In this study, PLF was produced by a novel technology [18], where the PLF was extracted by a decortication machine named the PLFM, as shown in Figure 1(b). An extraction process was performed to get the fibres by feeding the pineapple leaf into the PLFM. This machine used blades to remove the waxy layer on the pineapple leaf instead of forcing it out by crushing [18]. After the extraction process, the fibres underwent an alkaline treatment process with the aim of modifying the fibre surface. Firstly, the fibres were soaked in $5 \%$ of $\mathrm{NaOH}$ solution in a water reservoir for 1 hour at room temperature. Thereafter, the fibres were rinsed several times with distilled water, and then dried at room temperature for 48 hours [1]. The PLF after the alkaline treatment is shown in Figure 1(c). Undergoing the alkaline treatment can increase the tensile strength of the fibres, remove all the impurities and moisture content, stabilize the molecular orientation, treat the fibre surface, and also improve the adhesion between the hydrophilic PLF and hydrophobic PP [18, 24, 28, 32].

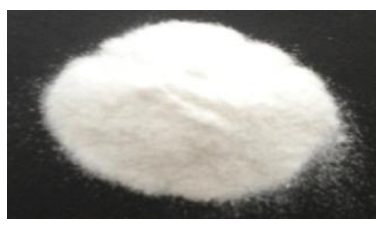

(a)

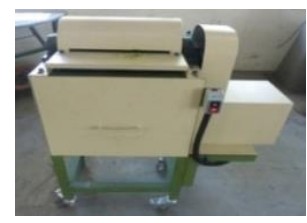

(b)

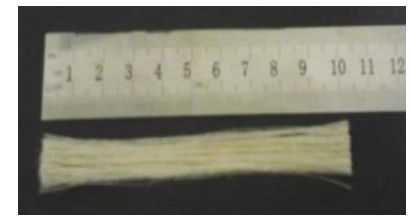

(c)

Figure 1. Polypropylene (a), pineapple leaf fibre machine (b), pineapple leaf fibre (c).

\section{Composite Preparation}

PLF/PP composites of different compositions were prepared by a manual mixing technique and were compression-moulded to form a sheet of composites. The composition of the PLF/PP composite by weight percentage (wt $\%$ ) of the fibre/matrix and each sample is shown in Table 2. The mould was first cleaned with wax so that the samples would easily come out of the mould after pressing. Fabrication of the composite samples begins by carefully placing the compound of the PLF and PP in a mould to ensure the unidirectional orientation of the fibres. The compound was then pressed to form a 3 $\mathrm{mm}$ thick sheet at a temperature of $190{ }^{\circ} \mathrm{C}$ under a pressure of $3.5 \mathrm{MPa}$ for 7 minutes, after undergoing the process of pre-heating for 5 minutes at the same temperature. This was followed by a cooling process for 30 minutes and the final result of the composites was formed into sheets and then cut for testing according to the ASTM standard by using a Proxxon saw.

\section{Measurement of Mechanical Properties}

A tensile test is performed according to ASTM D 3039: Standard Test Method for Tensile Properties of Polymer Matrix Composite Materials. The specimens having dimensions of $140 \mathrm{~mm}$ length, $13 \mathrm{~mm}$ width and $3 \mathrm{~mm}$ thickness were tested using an Instron Universal Testing Machine (Model 5585H) controlled by Bluehill 2 software with a $1 \mathrm{kN}$ load test and operated at constant head-speed tests of $2 \mathrm{~min} / \mathrm{mm}$. The specimen was fixed in the grips of the testing machine and load was applied hydraulically till rupture occurred. The values of tensile stress and the percentage of elongation were obtained from the stressstrain curve diagram. The density of the PLF/PP composite was measured using a digital electronic densimeter (MD-300S). The hardness of the PLF/PP composite was measured using an analogue Shore scale "D" type Durometer according to ASTM D1957. The hardness of the samples was measured by the depth of the indentation and the reading 
was registered on the dial indicator. The hardness characteristic tends to change at the edges of the sample, so this measurement should be taken at least $12 \mathrm{~mm}$ from the edge.

Table 2. Samples of PLF/PP composite for each composition.

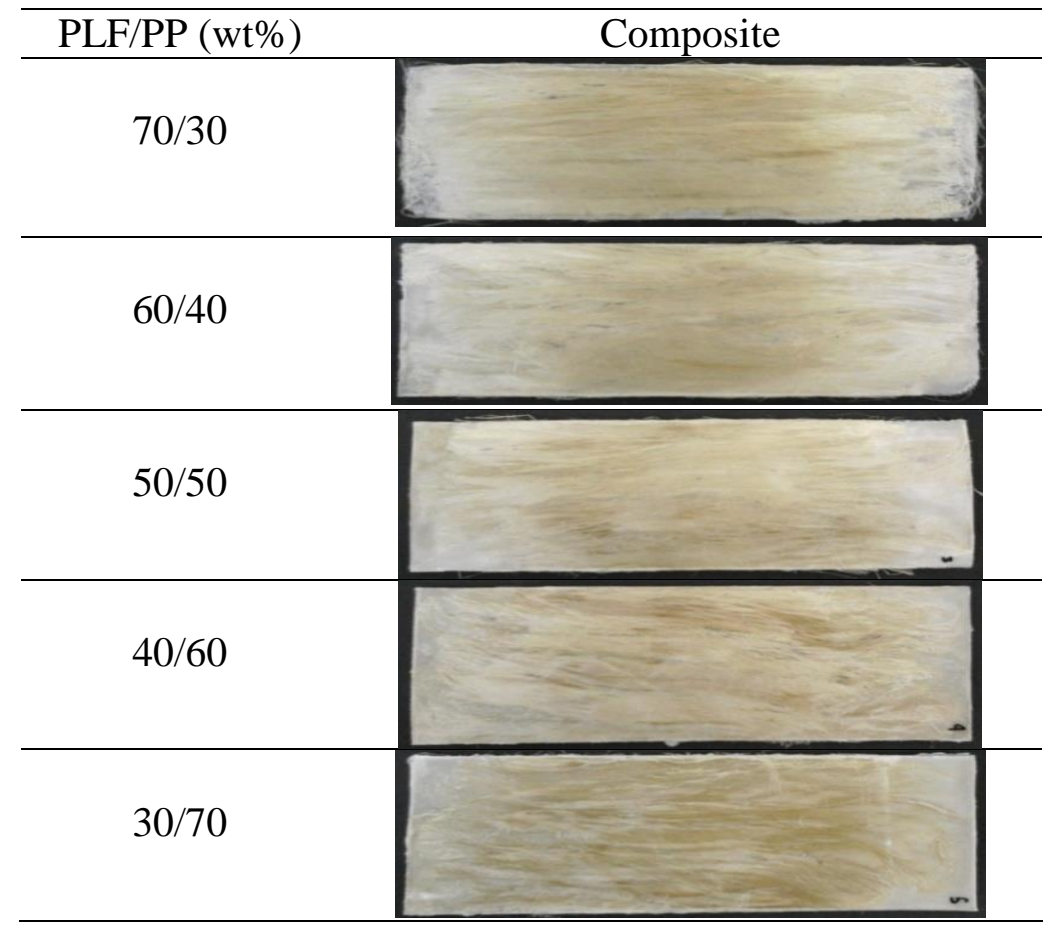

\section{RESULTS AND DISCUSSION}

Figure 2 shows the tensile strength with different PLF loadings for the PLF/PP composite in the longitudinal direction. Each of the error bars presented in the graphs is based on standard error bars to indicate that the obtained value is within the range of the true value. The behaviour of the composites changes considerably with increasing PLF loading. A maximum tensile strength up to about $70 \mathrm{MPa}$ was achieved at $70 \mathrm{wt} \%$ of PLF loading. The addition of $30 \mathrm{wt} \%$ fibre increased the tensile strength by $172 \%$ compared to the tensile strength of plain PP, while the addition of $70 \mathrm{wt} \%$ fibre increased the tensile strength by $354 \%$ compared to the tensile strength of plain PP. The increment trend is in agreement with other natural composites $[19,20,24]$. The results show that the tensile strength obtained is higher than the results obtained by other researchers [1, 12], who utilized different cultivars. Arib et al. [12] found tensile strength values of the composite in unidirectional orientation PLF (not mentioning the cultivar type) in the range of 30-38 $\mathrm{MPa}$. The higher result of the tensile strength in the current work can be attributed to the properties of the Josapine cultivar, as shown in Table 1, and the effect of surface modification of PLF through the alkaline treatment. Additionally, Kasim et al. [1]reported tensile strength values of composite in random orientation PLF (Sarawak cultivar) in the range of 3-17 MPa. This indicates that the PLF is stronger when in parallel to the tensile axis. 


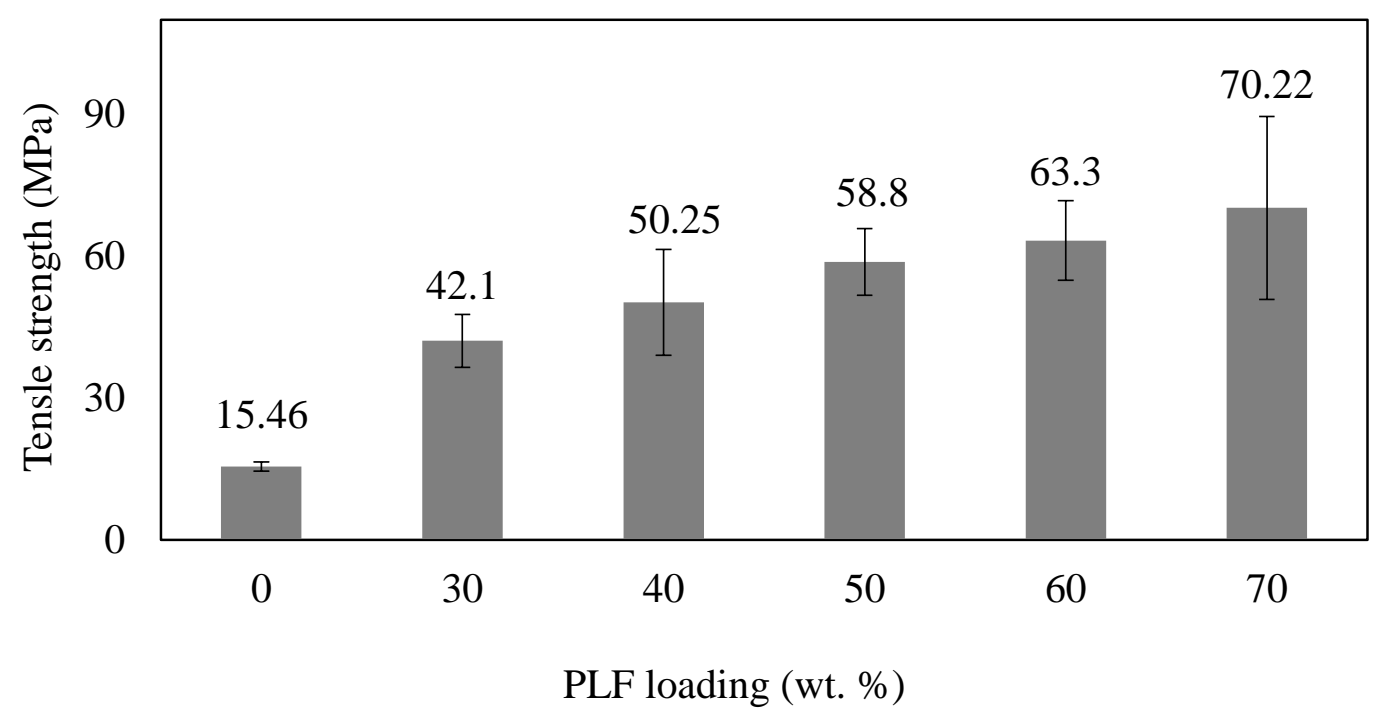

Figure 2. Tensile strength (MPa) versus PLF loading (wt.\%).

From Table 3, it can be seen that $70 \mathrm{wt} \%$ of PLF loading showed the highest value of tensile strength and strain. This is because greater fibre loading will enhance the strength of the composites. The function of the matrix is to transfer the forces to the fibres; hence if the fibre loading has been increased, it can withstand higher forces compared to lower fibre contents [33]. During preparation of the samples, PLF from the Josapine cultivar with the diameter range of 105-300 $\mu \mathrm{m}$ [13] was mixed with fine powder of PP $(250 \mu \mathrm{m})$ to produce the composites. This allows greater surface adhesion between the fibre and the matrix material to be bonded. Threepopnatkul et al. [23] stated that good adhesion between the fibres and matrix makes it feasible for stress transfer to take place from the matrix to the fibres, thereby improving the strength of the composite. In a natural manner, improvement of the tensile strength due to the addition of fibre content will have the effect of reducing the strain properties. However, the result obtained in this experiment shows the contrary, which is that the addition of fibre content improves the strain properties, as shown in Table 3. The occurrence of this phenomenon might be due to the nature of the Josapine cultivar, which shows superior strain properties compared to other cultivars [14]. Thus, the use of more Josapine fibres with alkaline treatment is expected to increase the strain properties in the composite, and good adhesion bonding has been developed between the PLF and PP due to the fact that the PP is in powder form.

Table 3. Tensile properties of the samples.

\begin{tabular}{cccc}
\hline $\begin{array}{c}\text { PLF loading } \\
(\mathrm{wt} \%)\end{array}$ & $\begin{array}{c}\text { Tensile strength, } \sigma \\
(\mathrm{MPa})\end{array}$ & $\begin{array}{c}\text { Young's modulus, E } \\
(\mathrm{GPa})\end{array}$ & $\begin{array}{c}\text { Strain, } \mathcal{E} \\
(\%)\end{array}$ \\
\hline 0 & 15.46 & 0.76 & 0.05 \\
30 & 42.1 & 2.98 & 0.03 \\
40 & 50.25 & 3.30 & 0.033 \\
50 & 58.8 & 3.93 & 0.037 \\
60 & 63.3 & 4.87 & 0.03 \\
70 & 70.22 & 3.08 & 0.05 \\
\hline
\end{tabular}


Figure 3 shows the comparison between the experimental and theoretical tensile strength versus PLF loading. The rule of mixture formula was used to compare the results of the experimental and theoretical tensile strength. The same equation was used by [12] and Luo et al. [24]. Theoretical calculations of the tensile strength in the longitudinal direction were carried out using the rule of mixture as shown in Eq. (1). Calculation of the volume fraction between the fibre and matrix was carried out using Eq. (2).

$$
\begin{gathered}
\sigma_{c}=\sigma_{m} V_{m}+\sigma_{f} V_{f} \\
V_{m}+V_{f}=1
\end{gathered}
$$

where $\sigma_{c}$ is the composite tensile strength, $\sigma_{m}$ is the matrix tensile strength, $\sigma_{f}$ is the fibre tensile strength, $V_{m}$ is the matrix volume fraction and $V_{f}$ is the fibre volume fraction. For example, calculate for $\sigma_{f}=293.08 \mathrm{MPa}, \sigma_{m}=15.46 \mathrm{MPa}, \mathrm{V}_{f}=70 \%, \mathrm{~V}_{m}=30 \%$.

Thus, $V_{f}+V_{m}=1 \Rightarrow V_{f}=1-V_{m} \Rightarrow V_{f}=1-0.3$.

$$
\sigma_{c}=\sigma_{f} V_{f}+\sigma_{m} V_{m}=(293.08)(0.7)+(15.46)(0.3)=209.79 \mathrm{MPa}
$$

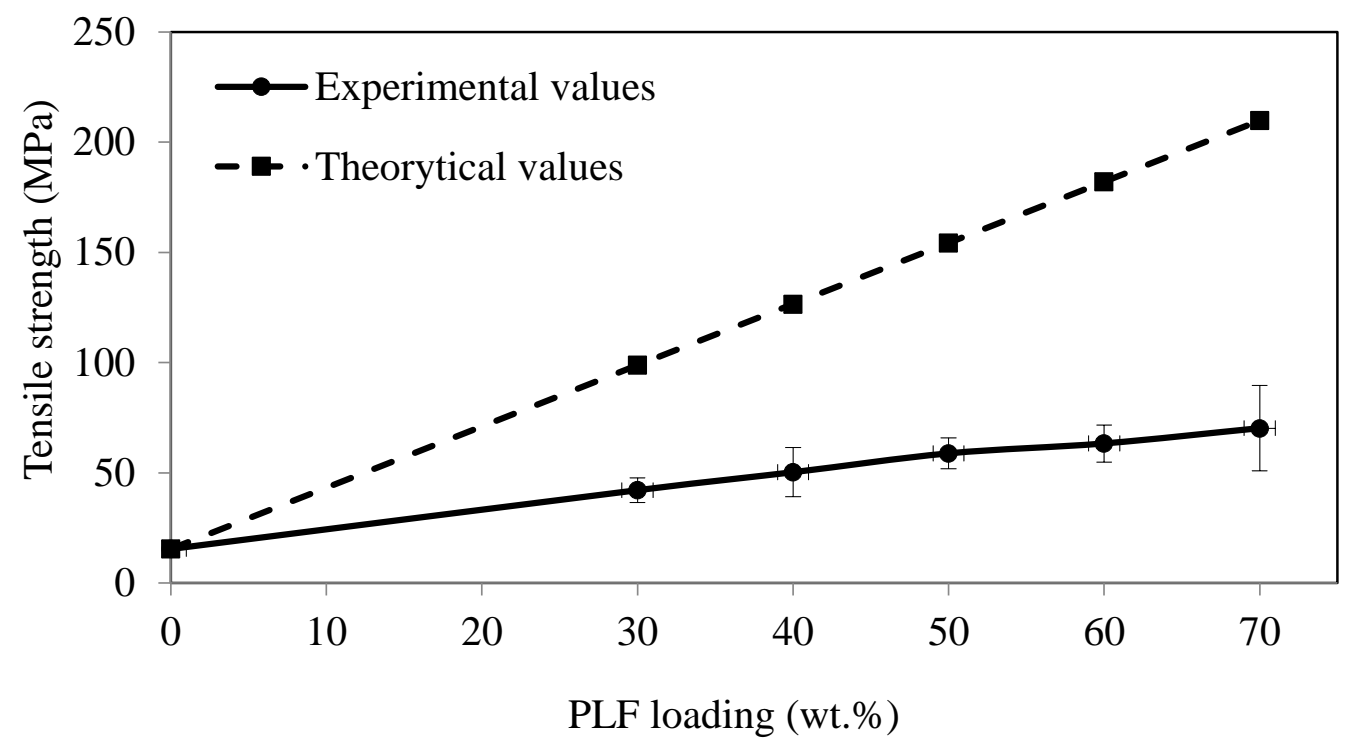

Figure 3.Comparison of experimental and theoretical tensile strength (MPa) versus PLF loading (wt.\%).

Comparison of the experimental and theoretical values for the tensile strength shows that the tensile strength increases with increment of the PLF loading. However, the experimental values are lower than the theoretical values. This may be because the fibres were not perfectly aligned and composites were poorly prepared. This is confirmed by the fact that some fibres were not perfectly aligned, as shown in Figure 4. Figure 5 shows the Young's modulus with different PLF loadings for the PLF/PP composite in the longitudinal direction. The graph shows that the Young's modulus increased with the increment of PLF loading except at $70 \mathrm{wt} \%$ PLF loading. The addition of $60 \mathrm{wt} \%$ fibre increased the Young's modulus by 538\% compared to the Young's modulus of plain PP, while the addition of $70 \mathrm{wt} \%$ fibre decreases the Young's modulus by $37 \%$. The increment 
in Young's modulus of the composite was caused by improved adhesion between the fibre and the matrix [23].

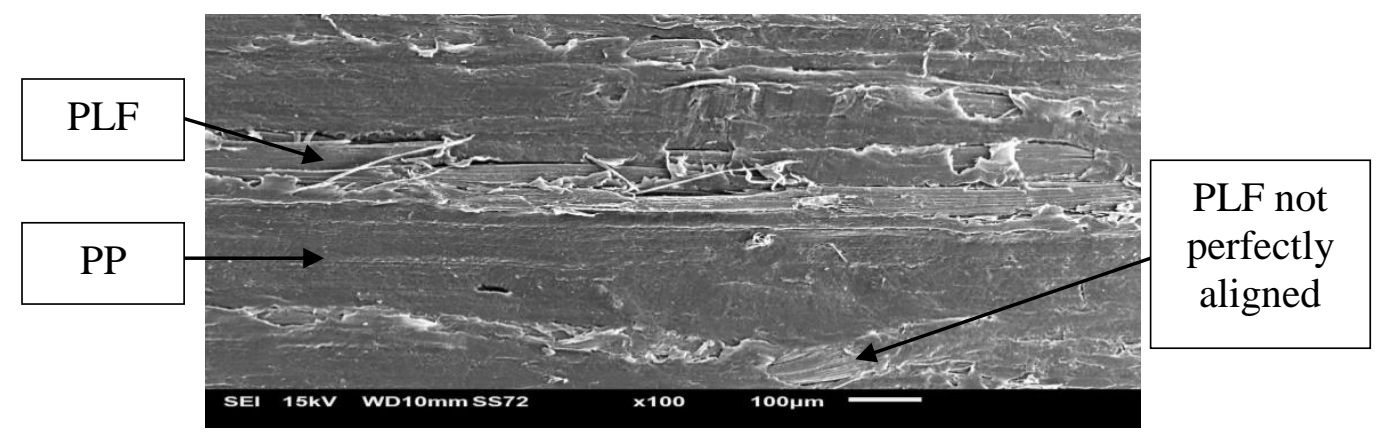

Figure 4. Imperfectly aligned fibres.

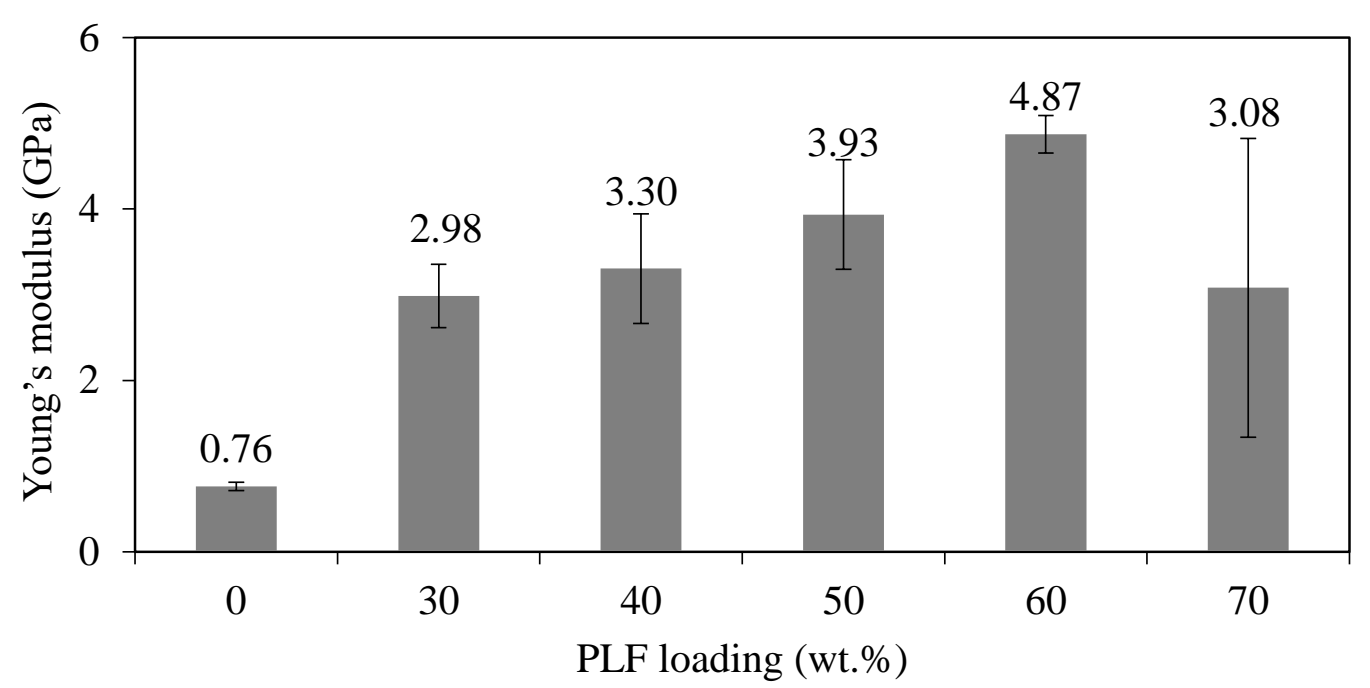

Figure 5. Young's modulus (GPa) versus PLF loading (wt.\%).

Figure 6 shows the comparison between the experimental and theoretical Young's modulus versus PLF loading. Theoretical calculations of the Young's modulus in the longitudinal direction were carried out using Eq. (3).

$$
E_{c}=E_{m} V_{m}+E_{f} V_{f}
$$

where $E_{c}$ is the composite Young's modulus, $\sigma_{m}$ is the matrix Young's modulus, and $\sigma_{f}$ is the fibre Young's modulus. For example, calculate for, $E_{f}=18.94 \mathrm{GPa}, E_{m}=0.76 \mathrm{GPa}$ $\mathrm{V}_{f}=70 \%, \mathrm{~V}_{m}=30 \%$.

Thus,

$$
E_{c}=E_{f} V_{f}+E_{m} V_{m}=(18.94)(0.7)+(0.76)(0.3)=13.49 \mathrm{GPa}
$$

Meanwhile, Figure 7 shows the graph of hardness (Shore-D) and density $\left(\mathrm{g} / \mathrm{cm}^{3}\right)$ versus PLF loading for the PLF/PP composite in the longitudinal direction. The result shows that the hardness and density increase with the increment of PLF loading. The 
addition of $30 \mathrm{wt} \%$ fibre increases the hardness by $0.53 \%$ and also increases the density by $6.93 \%$ compared to the hardness and density of plain PP. An increment of PLF loading up to $70 \mathrm{wt} \%$ shows a similar result to $30 \mathrm{wt} \%$ PLF loading. This increasing trend is in agreement with other natural composites [6, 13, 21]. George et al. [21] stated that the incorporation of fibres increases markedly the composite hardness. Hardness is related to the toughness and strength of the composite. The density of the composite has been increased with fibre content due to the close packing of the fibres. This indicates that the increment of PLF loading in PLF/PP composite increased the ability to resist more indentation and consequently resulted in a parallel increase of the density of the PLF/PP composite.

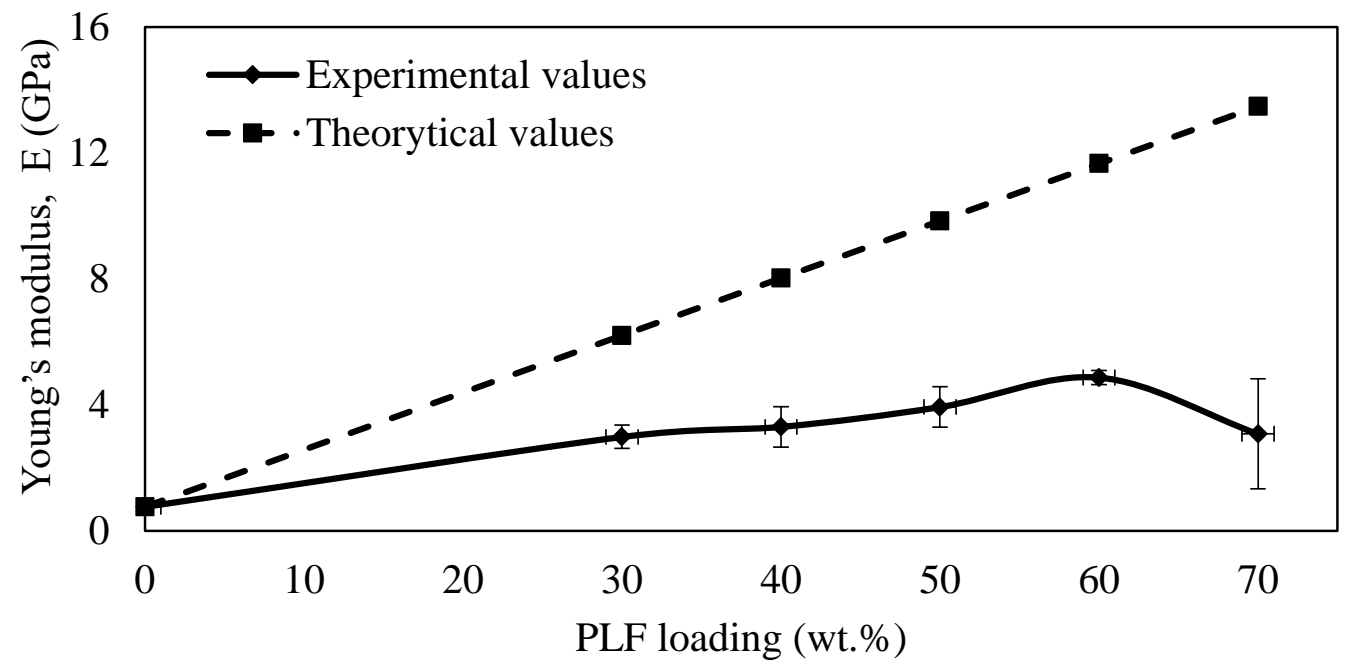

Figure 6. Comparison of experimental and theoretical Young's modulus (GPa) versus PLF loading (wt.\%).

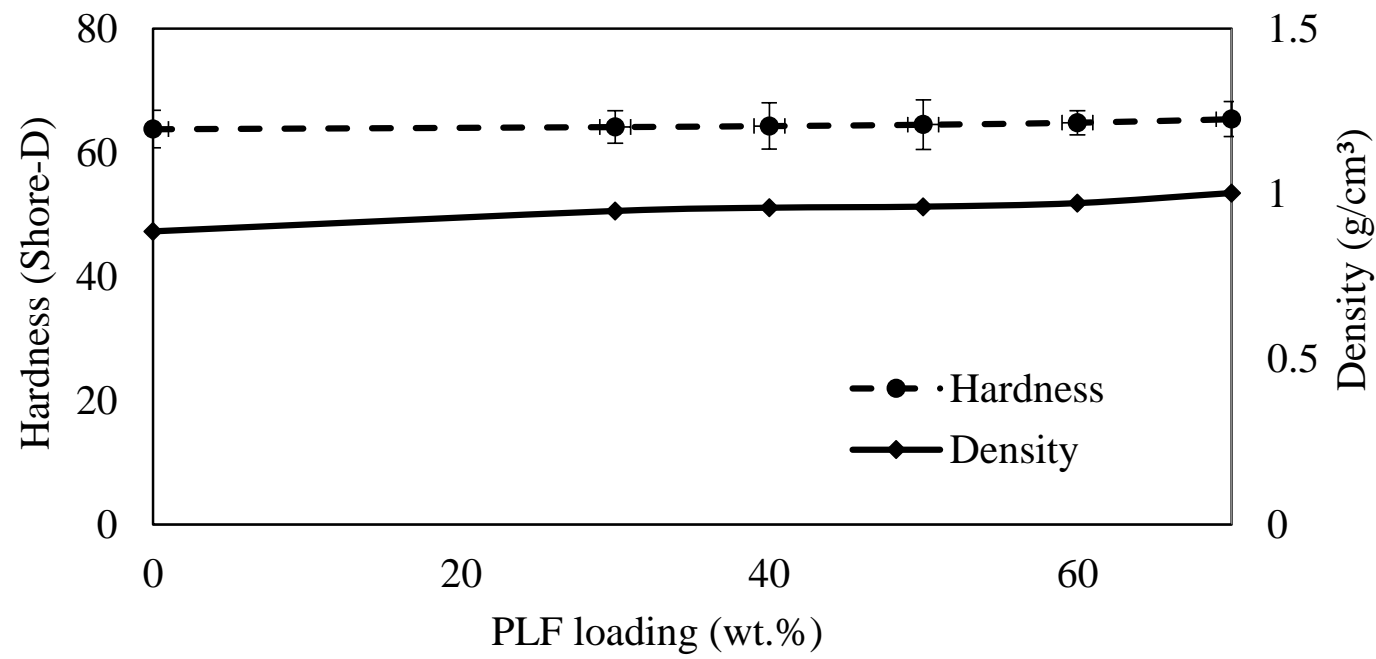

Figure 7. Hardness (Shore-D) and density $\left(\mathrm{g} / \mathrm{cm}^{3}\right)$ versus PLF loading (wt.\%).

\section{CONCLUSION}

The mechanical properties of impact polypropylene composite reinforced with PLF from the Josapine cultivar as a function of fibre loading have been studied and determined. The 
results of the present study revealed that the PLF fibre loading with alkaline treatment greatly influences the mechanical properties of PLF/PP composite. Based on the results of the tensile properties, hardness and density, it can be concluded that the PLF/PP composite with the composition ratio of $60 / 40$ shows the best mechanical properties compared with other composition ratios (30/70, 40/60, 50/50 and 70/30), which are 63.3 $\mathrm{MPa}, 64.83$ Shore-D and $0.9716 \mathrm{~g} / \mathrm{cm}^{3}$ respectively. It was also found that the fibres distribution is not perfectly aligned and affects the mechanical properties of the PLF/PP composites. Improvement of the fibres distribution during the fabrication process and addition of maleic-anhydride-grafted polypropylene (MAPP) or polylactide (PLA) to improve the adhesion between the PLF and PP will be the focus in our future work.

\section{ACKNOWLEDGEMENT}

The authors would like to thank the Malaysia Ministry of Higher Education, Malaysia Ministry of Science, Technology and Innovation for sponsoring this work under Grant FRGS/2/2014/SG06/FKM/02/F00237 and Advanced Material Research Group (AMAT), Faculty Mechanical Engineering, University Teknikal Malaysia Melaka (UTeM) for financially sponsoring, facilities and gratefully knowledge during this research.

\section{REFERENCES}

[1] Kasim A, Selamat M, Aznan N, Sahadan S, Daud M, Salleh S, et al. Effect of pineapple leaf fiber loading on the properties of pineapple leaf fiberpolypropylene composite. Proceedings of Mechanical Engineering Research Day 2015. 2015;2015:3-4.

[2] Rahman MM, Jeffrey KJT. Residual strength of chop strand mats glass fiber/epoxy composite structures: effect of temperature and water absorption. International Journal of Automotive and Mechanical Engineering 2011;4:504-19.

[3] Sapuan SM, Bachtiar D, Hamdan MM. Flexural properties of alkaline treated sugar palm fibre reinforced epoxy composites. International Journal of Automotive and Mechanical Engineering. 2010;1:79-90.

[4] Alves C, Silva A, Reis L, Freitas M, Rodrigues L, Alves D. Ecodesign of automotive components making use of natural jute fiber composites. Journal of Cleaner Production. 2010;18:313-27.

[5] Kengkhetkit N, Amornsakchai T. A new approach to "Greening" plastic composites using pineapple leaf waste for performance and cost effectiveness. Materials \& Design. 2014;55:292-9.

[6] Prasad AR, Rao KM. Mechanical properties of natural fibre reinforced polyester composites: Jowar, sisal and bamboo. Materials \& Design. 2011;32:4658-63.

[7] Roslan SAH, Hassan MZ, Rasid ZA, Zaki SA, Daud Y, Aziz S, Sarip S, Ismail Z. Mechanical properties of bamboo reinforced epoxy sandwich structure composites. International Journal of Automotive and Mechanical Engineering. 2015;12: 2882-92.

[8] M. Khairul Zaimy AG, Zafiah A, Rus M, Ab Latif N, Nurulsaidatulsyida S. Mechanical and thermal properties of waste bio-polymer compound by hot compression molding technique. Journal of Mechanical Engineering and Sciences. 2013;5:582-91. 
[9] Shymraj R, Sivasubramanian P, Dhanusha PB. Investigations on mechanical properties of pineapple fiber reinforced polymer composite material. International Journal of Scienctific Research. 2013; 4(8): 1-5.

[10] Dhal JP, Mishra SC. Processing and properties of natural fiber-reinforced polymer composite. Journal of Materials. 2012;2013.

[11] Hardinnawirda K, SitiRabiatull Aisha I. Effect of Rice Husks as Filler in Polymer Matrix Composites. Journal of Mechanical Engineering and Sciences. 2012;2:181-6.

[12] Yusoff M, Zuhri M, Salit MS, Ismail N, Wirawan R. Mechanical properties of short random oil palm fibre reinforced epoxy composites. Sains Malaysiana. 2010;39:87-92.

[13] Mohamed A, Sapuan S, Khalina A. Selected properties of hand-laid and compression molded vinyl ester and pineapple leaf fiber (PALF)-reinforced vinyl ester composites. International Journal of Mechanical and Materials Engineering. 2010;5:68-73.

[14] Mohamed A, Sapuan S, Shahjahan M, Khalina A. Characterization of pineapple leaf fibers from selected Malaysian cultivars. Journal of Food, Agriculture \& Environment. 2009;7:235-40.

[15] Zakikhani P, Zahari R, Sultan M, Majid D. Bamboo fibre extraction and its reinforced polymer composite material. International Journal of Chemical, Molecular, Nuclear, Materials and Metallurgical Engineering. 2014;8:322-4.

[16] Li X, Tabil LG, Panigrahi S. Chemical treatments of natural fiber for use in natural fiber-reinforced composites: a review. Journal of Polymers and the Environment. 2007; 15:25-33.

[17] Yusof Y, Yahya SA, Adam A. Novel technology for sustainable pineapple leaf fibers productions. Procedia CIRP. 2015;26:756-60.

[18] Yusof Y, Adam A. Review on PALF extraction machines for natural fibers. Advanced Materials Research: Trans Tech Publ; 2013. p. 2699-703.

[19] Vinod B, Sudev L. Effect of Fiber Orientation on the Flexural Properties of PALF Reinforced Bisphenol Composites. International Journal of Science and Engineering Applications. 2013;2:166-9.

[20] Wisittanawat U, Thanawan S, Amornsakchai T. Mechanical properties of highly aligned short pineapple leaf fiber reinforced-nitrile rubber composite: effect of fiber content and bonding agent. Polymer Testing. 2014;35:20-7.

[21] George J, Bhagawan S, Prabhakaran N, Thomas S. Short pineapple-leaf-fiberreinforced low-density polyethylene composites. Journal of Applied Polymer Science. 1995;57:843-54.

[22] Devi LU, Bhagawan S, Thomas S. Mechanical properties of pineapple leaf fiberreinforced polyester composites. Journal of Applied Polymer Science. 1997;64:1739-48.

[23] Threepopnatkul P, Kaerkitcha N, Athipongarporn N. Effect of surface treatment on performance of pineapple leaf fiber-polycarbonate composites. Composites Part B: Engineering. 2009;40:628-32.

[24] Luo S, Netravali A. Mechanical and thermal properties of environment-friendly "green" composites made from pineapple leaf fibers and poly (hydroxybutyrateco-valerate) resin. Polymer Composites. 1999;20:367-78.

[25] Romli FI, Alias AN, Rafie ASM, Majid DLAA. Factorial study on the tensile strength of a coir fiber-reinforced epoxy composite. AASRI Procedia. 2012;3:242-7. 
[26] Mwaikambo LY, Ansell MP. Chemical modification of hemp, sisal, jute, and kapok fibers by alkalization. Journal of Applied Polymer Science. 2002;84:222234.

[27] Hussain SA, Pandurangadu V, Palanikuamr K. Mechanical properties of green coconut fiber reinforced HDPE polymer composite. International Journal of Engineering Science and Technology. 2011;3:7942-52.

[28] Zakaria S, Hamzah H, Murshidi JA, Deraman M. Chemical modification on lignocellulosic polymeric oil palm empty fruit bunch for advanced material. Advances in Polymer Technology. 2001;20:289-95.

[29] Taufik RS, Adibah M NF, Muhamad MR, Hasib H. Feasibility Study of Natural Fiber Composite Material for Engineering Application. Journal of Mechanical Engineering and Sciences. 2014;6:940-8.

[30] Aeyzarq Muhammad Hadzreel MR, Siti Rabiatull Aisha I. Effect of Reinforcement Alignment on the Properties of Polymer Matrix Composite. Journal of Mechanical Engineering and Sciences. 2013;4:548-54.

[31] Bhaskar HB, Sharief A. Effect of Solutionizing on Dry Sliding Wear of A12024Beryl Metal Matrix Composite. Journal of Mechanical Engineering and Sciences. 2012;3:281-90.

[32] Siregar JP, Salit MS, Ab Rahman MZ, Dahlan M, Zaman K. Effects of alkali treatments on the tensile properties of pineapple leaf fibre reinforced high impact polystyrene composites. Pertanika Journal of Science \& Technology. 2012;20:409-14.

[33] Matthews FL, Davies G, Hitchings D, Soutis C. Finite element modelling of composite materials and structures: Elsevier; 2000. 